\title{
Estudo do Plano de Gerenciamento Integrado de Resíduos Sólidos do Município de Cotiporã - RS
}

\author{
Study of the Integrated Municipal Solid Waste Management of Cotiporã - RS
}

\author{
Edenara De Marco, Luciara Bilhalva Corrêa
}

Universidade Federal de Pelotas

\begin{abstract}
Resumo
O crescimento urbano desordenado tem causado uma série de impactos ambientais e preocupações por parte da população e seus gestores. Assim, o desafio da sustentabilidade urbana passou a ocupar um papel de destaque dentre os eixos estratégicos nos órgãos ambientais do país. Buscando minimizar os impactos ambientais, sociais, econômicos e transformar o cenário ambiental atual, a Lei 12.305/10 que institui a Política Nacional de Resíduos Sólidos (PNRS), estabelece a obrigatoriedade de elaboração de Planos Municipais de Gerenciamento Integrado de Resíduos Sólidos (PMGIRS). A fim de adequar-se à legislação, o Município de Cotiporã/RS elaborou seu PMGIRS no ano de 2012, é a partir dele que realizamos um estudo técnico e bibliográfico, propiciando uma análise a fim de estabelecer um melhor andamento das metas e ações realizadas no cumprimento do Plano. Realizou-se pesquisa documental do PMGIRS e diagnóstico in loco da situação atual do manejo dos Resíduos Sólidos, após a implantação do Plano. É possível constatar que a administração pública vem empenhando esforços no cumprimento do plano. As recomendações técnicas propostas poderão ser revistas na continuidade da implementação do PMGlRS e incorporadas às ações que já vem sendo realizadas, propiciando melhoria continua, atualização e adequação do Plano.
\end{abstract}

Palavras-chave: Saneamento. Política Nacional de Resíduos Sólidos. Sustentabilidade.

\begin{abstract}
Abstract The disorderly urban growth has caused a number of environmental impacts and concerns among the population and their managers. The challenge of urban sustainability has come to occupy a prominent role among the strategic priorities in the environmental agencies of the country. Seeking to minimize the environmental, social, economic impacts and to transform the current environmental scenario, the law 12.305/10 that institutes the National Policy of Solid Waste (NPSW), establishes the obligatoriness of elaborating plans for the Integrated Municipal Solid Waste Management (IMSWMRS). In order to adapt to the law, the City of Cotiporã/RS elaborated its IMSWM in 2012, it is from this that we perform a technical and bibliographical study, providing an analysis in order to establish a better progress of goals and actions performed fulfilling to the Plan. We conducted documentary research IMSWM and in situ diagnosis of the current situation of the management of Solid Waste, after the implementation of the Plan. It can be seen that the government is making efforts to fulfill the plan. The proposed technical recommendations may be revised in the continuing implementation of IMSWMRS and incorporated to the actions already being carried out, providing continuous improvement, adaptation and adequacy of the Plan.
\end{abstract}

Keywords Sanitation. National Policy of Solid Waste (NPSW). Sustainability. 


\section{Introdução}

No Brasil, observam-se grandes problemas de ordem social, econômica e ambiental que estão relacionados ao nosso modelo de desenvolvimento, o qual tem como pressuposto básico a produção e o consumo de bens; num sistema que visa a obtenção de lucro imediato sem a preocupação com a sustentabilidade ambiental e com grande parcela da população excluídas socialmente do modelo vigente. Um dos sinais mais visíveis do modelo não sustentável da sociedade moderna é a crescente produção e disposição dos resíduos sólidos. A geração de resíduos deve ser vista tanto pela quantidade gerada como pela sua diversidade, e ela representa desperdício de matéria-prima e energia, bem como degradação e poluição ambiental (AQUINO, 2007).

A geração total de Resíduos Sólidos Urbanos (RSU) no Brasil em 2014 foi de aproximadamente 78,6 milhões de toneladas, o que representa um aumento de 2,9\% de um ano para outro, índice superior à taxa de crescimento populacional no país no período, que foi de $0,9 \%$. Os dados de geração anual teve um aumento de 2,09\% em 2014 e o aumento da geração per capita em 2014 foi de 2,02\%, comparados com 2013 (ABRELPE, 2014).

RSU segundo a Política Nacional de Resíduos Sólidos (PNRS) são os resíduos domiciliares e de limpeza urbana. Resíduos Domiciliares: os originários de atividades domésticas em residências urbanas. Resíduos de Limpeza Urbana: os originários da varrição, limpeza de logradouros e vias públicas e outros serviços de limpeza urbana (BRASIL, 2010).

A disposição inadequada de RSU é um dos principais fatores agravantes da atual crise ambiental em que nos encontramos, além de impactar de forma negativa o ambiente, ocasiona sérios riscos a saúde pública. O problema do descarte dos resíduos sólidos urbanos está diretamente relacionado ao aumento crescente de sua produção, o gerenciamento inadequado e a falta de locais adequados para a sua disposição. Países em desenvolvimento, como o Brasil, vêm buscando, cada vez mais, atividades que reduzam a produção de resíduos e maneiras de destinação correta para os mesmos (MANO, et al., 2010).

Merecem destaque os números relacionados à destinação final dos resíduos coletados pela Abrelpe (2014), cuja pesquisa revelou que 58,4 \% dos RSU tiveram destinação adequada e seguiram para aterros sanitários em 2014, praticamente sem alteração do cenário registrado no ano anterior. Nesse sentido, é importante ressaltar que os $41,6 \%$ restantes correspondem a 81 mil toneladas diárias, que são encaminhadas para lixões ou aterros controlados, os quais pouco se diferenciam dos lixões, uma vez que ambos não possuem o conjunto de sistemas e medidas necessários para proteção do meio ambiente contra danos e degradações.

Os municípios tiveram o prazo até agosto do ano de 2014, segundo a PNRS para realizar os seus respectivos Plano Municipal de Gestão Integrada de Resíduos Sólidos (PMGIRS), uma política ambiental de fundamental importância que atinge dimensões sociais, econômicas e ambientais, na busca do desenvolvimento sustentável (BRASIL., 2013). A cidade de Cotiporã/RS desenvolveu seu PMGIRS no ano de 2012, visando à adequação às exigências impostas pela PNRS. O Plano apresenta ações relativas ao manejo de resíduos sólidos produzidos no Município e as adequações necessárias para uma destinação correta através de diretrizes e orientações. Este trabalho tem por objetivo a análise quantitativa e qualitativa dos resíduos sólidos urbanos do município de Cotiporã e apontar melhorias para a adequada destinação dos resíduos sólidos urbanos. 


\section{Metodologia}

\section{1 Área de Estudo}

Município de Cotiporã está localizado no Estado do Rio Grande do Sul, na Mesorregião Nordeste Rio-Grandense e na microrregião de Caxias do Sul, conforme IBGE (2010). Cotiporã situa-se entre as coordenadas $28^{\circ} 59^{\prime} 40^{\prime \prime}$ de Latitude Sul e 51ำ41'45" de Longitude Oeste e possui uma área de 172,37 $\mathrm{km}^{2}$. O Município apresenta uma população total de 3.917 habitantes, sendo 2.048 moradores na zona urbana e 1.869 moradores na zona rural, conforme dados estatísticos do Instituto Brasileiro de Geografia e Estatística (IBGE), censo do ano de 2010. A principal atividade econômica é a agricultura, com algumas culturas de longa duração uva e com culturas temporárias como milho. Na pecuária destaca-se o rebanho de bovinos e galináceos.

Foi realizada uma pesquisa buscando a situação atual em relação ao Gerenciamento de Resíduos Sólidos no Município de Cotiporã/RS. Para o recolhimento de dados e o conhecimento das ações para aplicação do PMGIRS efetuou-se um diagnóstico utilizando um formulário para melhor eficiência na coleta de dados. Os dados foram fornecidos pela Prefeitura Municipal de Cotiporã através do PMGIRS e suas Secretarias, com destaque, pela Secretaria do Meio Ambiente, além de serem utilizados dados do IBGE.

\subsection{Levantamento de Dados}

Inicialmente foi realizada uma pesquisa bibliográfica com foco no PMGIRS do Município de Cotiporã/RS, posteriormente foi realizada um diagnóstico com a coleta de dados da situação atual após a criação do Plano. Foram descritas as ações realizadas e as metas propostas pelo Plano, as que estão em andamento e as que serão realizadas em curto prazo. Para a conclusão do trabalho foram propostas ações e observações para o melhor andamento e cumprimento do Plano.

\subsection{Estudo Documental PMGIRS}

Este trabalho baseou-se no PMGIRS do Município de Cotiporã, foi realizado um estudo da implantação do Plano e das condições em que ele se encontra atualmente, em relação a ações quanto à coleta seletiva; associação de catadores, educação ambiental.

\subsection{Diagnóstico in loco dos RS}

Para a efetivação do diagnóstico utilizou-se um formulário para preenchimento de dados, pôde-se observar dados referentes à situação de produção, coleta, processamento, destinação e disposição final de resíduos sólidos, serviços de limpeza urbana, varrição e capina, estação de transferência, entulho, resíduos de serviço de saúde, catadores, coleta seletiva, previsões futuras e cumprimento das metas de curto prazo propostas no PMGIRS.

\section{Resultados e Discussão}

\subsection{Diagnóstico dos Resíduos Sólidos}

Paralelo ao estudo do PMGIRS do Município de Cotiporã, o diagnóstico constituiu uma ferramenta de fundamental importância para o estudo do gerenciamento dos resíduos sólido, uma vez que permitiu conhecer a situação atual, o prognóstico para o futuro, bem como, os recursos humanos, materiais e financeiros que o Município dispõe e os que poderão ser obtidos. Foi identificado que o Município em estudo não dispõe de dados históricos em relação à geração de resíduos sólidos domiciliares, ou acompanhamentos recentes referentes à produção de resíduos 
sólidos. Por conseguinte, foram utilizados dados de amostragens realizadas no ano de 2012 e algumas informações atualizadas, visando à obtenção de dados relativos aos aspectos qualiquantitativos dos resíduos sólidos.

\subsection{Caracterização e quantificação gravimétrica dos Resíduos Sólidos}

As informações referentes à caracterização e quantificação foram extraídas do Plano Municipal de Gerenciamento Integrado de Resíduos Sólidos (PMGIRS) de Cotiporã e adquiridas através da aplicação do Formulário do Diagnóstico. Na Tabela 1 estão apresentados os dados referentes às amostragens realizadas, bem como as condições climáticas e as respectivas quantidades de resíduos orgânicos e inorgânicos.

As duas amostragens realizadas (17/09 e 11/10 de 2012) possibilitou caracterizar a geração de resíduos provenientes da área urbana do Município. Na primeira amostragem, foram coletados 20,70 $\mathrm{Kg}$ de resíduos, os quais foram separados por tipologia. Na segunda amostragem, foram analisados $25,20 \mathrm{Kg}$ de resíduos, os quais também foram separados por tipologia.

Tabela 1 - Amostragem dos Resíduos do Município de Cotiporã

\begin{tabular}{lllllll}
\hline Amostragem & Data & $\begin{array}{l}\text { Condições } \\
\text { Climáticas }\end{array}$ & Orgânico (Kg) & $\%$ & Inorgânico (Kg) & $\%$ \\
\hline 01 & $17 / 09 / 2012$ & $\begin{array}{l}\text { Parcialmente } \\
\text { Nublado }\end{array}$ & 12,20 & 58,94 & 8,5 & 41,06 \\
\hline 02 & $11 / 10 / 2012$ & $\begin{array}{l}\text { Parcialmente } \\
\text { Nublado }\end{array}$ & 18,85 & 74,80 & 6,35 & 25,20 \\
\hline & Média Total & 15,52 & 66,87 & 7,42 & 66,40 \\
\hline
\end{tabular}

Fonte: BRASIL, 2012.

Para melhor análise dos resíduos foi realizada a caracterização e quantificação gravimétrica (traduz o percentual de cada componente em relação ao peso total de lixo) dos resíduos sólidos domiciliares através de amostragem.

O objetivo da amostragem é a obtenção de uma amostra representativa, ou seja, a coleta de uma parcela do resíduo a ser estudado que, quando analisado, apresente as mesmas características e propriedades de sua massa total (BRASIL, 2013).

Pessin et al. (2006) afirma que para uma gestão racional e definição de uma disposição final ambientalmente segura, é preciso realizar um diagnóstico dos resíduos gerados, destacando-se a determinação da composição gravimétrica ou caracterização quali-quantitativa dos mesmos.

O procedimento adotado para a coleta das amostras representativas foi do tipo amostragem em montes ou pilhas de resíduos. Esta etapa consistiu em retirar quatro amostras de três seções (do topo, do meio e da base). Após a coleta das alíquotas, foi realizada a pesagem individual, rompimento dos sacos plásticos e a segregação conforme a sua tipologia e pesados para diagnosticar a sua porcentagem em peso (BRASIL, 2012).

As percentagens de cada resíduo, coletados nas análises quantitativa e qualitativa dos resíduos sólidos realizadas para implantação do PMGIRS de Cotiporã, podem ser observadas na Tabela 2. 
Tabela 2 - Quantificação e caracterização gravimétrica dos resíduos sólidos do município de Cotiporã

\begin{tabular}{lllllll}
\hline \multirow{2}{*}{ Amostragem } & $\begin{array}{l}\text { Total de } \\
\text { Resíduos (Kg) }\end{array}$ & $\begin{array}{l}\text { Resíduos } \\
\text { Inorgânicos (\%) }\end{array}$ & $\begin{array}{l}\text { Plásticos } \\
\text { Diversos (\%) }\end{array}$ & $\begin{array}{l}\text { Papel e } \\
\text { Papelão (\%) }\end{array}$ & $\begin{array}{l}\text { Latas } \\
\text { Metálicas (\%) }\end{array}$ & \multirow{2}{*}{ Rejeitos (\%) } \\
\hline 1 & 20,70 & 41,06 & 31,90 & 6,76 & 1,20 & 1,20 \\
\hline 2 & 25,20 & 25,20 & 11,30 & 3,80 & 3,15 & 3,80 \\
\hline
\end{tabular}

Fonte: BRASIL, 2012.

Os dados observados na Tabela 2 assemelham-se aos de nível nacional trazidos pela Abrelpe em 2012, onde os plásticos apresentam 13,5\% na participação dos principais materiais no total de RSU (incluindo os resíduos orgânicos), papel e papelão apresentaram 13,1\%, metais 2,9\% e outros 16,7\%. Ainda segundo a Abrelpe (2014), o Brasil coleta em média 189.219 toneladas de RSU por dia.

A produção de resíduos orgânicos apresentou maior proporção nos resultados da análise gravimétrica, indicando a falta de conhecimento da população na utilização de resíduos orgânicos para fins de compostagem. Essa situação se assemelha a situação nacional, onde em 2012 apresentou 51,4 \% de matéria orgânica na participação dos principais materiais de Resíduos Sólidos Urbanos coletados no Brasil (ABRELPE, 2012).

Segundo Loureiro et al., (2007), as áreas urbanas caracterizam-se pela alta produção de resíduos orgânicos, tanto de origem domiciliar quanto de áreas comerciais e industriais como padarias e açougues, entre outras. Esses resíduos geralmente são aterrados, e constituem-se não só em grande preocupação das municipalidades, relacionada ao saneamento ambiental, como também em desperdício de nutrientes. A adequação da reciclagem desses resíduos resolve a questão ambiental e, em contrapartida, promove a geração de insumos orgânicos para a agricultura.

A coleta e o transporte do resíduo é a parte mais sensível aos olhos da população e mais passível de crítica. Deve funcionar bem e de forma sistemática. O Município de Cotiporã aderiu no ano de 2013, à Coleta Seletiva, termo utilizado para o recolhimento dos materiais que são possíveis de serem reciclados (inorgânicos), previamente separados na fonte geradora. Dentre estes materiais recicláveis estão os diversos tipos de papéis, plásticos, metais e vidros. A separação na fonte evita a contaminação dos materiais reaproveitáveis dos orgânicos, aumentando o valor agregado e diminuindo os custos de reciclagem. A Coleta Seletiva facilita a comercialização, estimula a cidadania e a participação popular, permite a articulação e participação de Associação de Catadores reduz a quantidade de resíduos destinados ao Aterro Sanitário.

De acordo com Monteiro e Zveibil (2001) as principais vantagens da implantação de cooperativas de catadores são: geração de emprego e renda; resgate da cidadania dos catadores, em sua maioria moradores de rua; redução das despesas com os programas de reciclagem; organização do trabalho dos catadores nas ruas, evitando problemas na coleta de resíduos e o armazenamento de materiais em logradouros públicos; redução de despesas com a coleta, transferência e disposição final dos resíduos separados pelos catadores, e que, dessa forma, não serão coletados, transportados e dispostos em aterro pelo sistema de limpeza urbana da cidade. Essa economia pode e deve ser revertida para as cooperativas de catadores, não em recursos financeiros, mas em forma de investimentos em infraestrutura (galpões de reciclagem, carrinhos padronizados, prensas, elevadores de fardos, uniformes), de modo a permitir a valorização dos resíduos recicláveis nesse novo mercado.

Segundo Ribeiro e Lima (2000), coleta seletiva é o reaproveitamento de resíduos que normalmente chamamos de lixo e deve sempre fazer parte de um sistema de gerenciamento integrado de resíduo. Nas cidades, a coleta seletiva é um instrumento concreto de incentivo a redução, a reutilização e a separação do material para a reciclagem, buscando uma mudança de comportamento, principalmente em relação aos desperdícios inerentes à sociedade de consumo. Dessa forma, compreende-se que é preciso minimizar a produção de rejeitos e maximizar a reutilização, além de diminuir os impactos ambientais negativos decorrentes da geração de resíduos sólidos. 
A Coleta Seletiva foi implantada no Município após a realização do PMGIRS, em junho de 2013. Os dados da coleta seletiva foram adquiridos através de uma visita in loco. A coleta é realizada e operada pela Administração Municipal na área Urbana e pela Empresa Adeva em algumas comunidades da área rural, com segregação na fonte (domicílios) e tem abrangência em cem por cento do Município.

A coleta dos resíduos sólidos gerados na área urbana e rural do Município é realizada em datas pré-estabelecidas, atendendo $100 \%$ da área. A frequência de coleta dos resíduos orgânicos na área urbana é três vezes por semana no período matinal, e a coleta seletiva é uma vez por semana, no período da tarde. Na área rural ocorre somente uma vez na semana a coleta de resíduos. Quanto ao tempo de coleta, o mesmo tem a duração de aproximadamente duas horas.

A Cidade possui uma Associação de Catadores que encontra-se em fase de regularização ambiental - obtenção de Licença de Operação junto à Prefeitura Municipal de Cotiporã. Esta Associação efetua a coleta e a separação de alguns resíduos do Município com intuito de incentivar a destinação de materiais à reciclagem e obtenção de renda.

A implantação e a operação da Associação de Catadores do Município, localizado na Linha Independência, era bastante preocupante, visto que os catadores acabavam realizando a triagem em condições extremamente precárias, sujeitas a todo tipo de contaminação e doenças, além de estocarem os materiais em sua própria residência, em condições e local impróprio para tal atividade. O local passou por adequações e está praticamente pronto para a realização da atividade.

Um programa de coleta seletiva deve contemplar o trabalho dos catadores locais. Estima-se que hoje, no Brasil, a atuação de cerca de 800 mil catadores de rua (autônomos e em cooperativas), responsáveis pela coleta de vários materiais. A valorização do trabalho dos catadores permite não só ganhos econômicos, mas sociais (BRASIL, 2013).

A PNRS visa incentivar a reciclagem, tanto por parte do consumidor como por parte do setor empresarial, promovendo ações compatíveis com os princípios da responsabilidade compartilhada dos geradores de resíduos e da logística reversa. Neste quesito cabe também incentivar a indústria da reciclagem com inclusão social, baseada na inserção dos catadores (BRASIL, 2010).

As metas expostas no PMGIRS são compromissos assumidos e que não devem ser esquecidos, eles visam a execução de ações planejadas de forma racional e integrada a fim de assegurar a limpeza da cidade, proteção do meio ambiente, assegurando saúde e bem estar da população e economia dos recursos públicos. O gerenciamento integrado de resíduos requer alguns compromissos: Implementar programas que estimulem a diminuição da geração de resíduos; Implementar pesquisas de tecnologias não-agressivas ao meio ambiente e compatíveis com a realidade socioeconômica; Desenvolver programas de educação ambiental com ênfase na produção e tratamento de resíduos; Minimizar a disposição dos resíduos, estabelecendo programas de pré-seleção, reciclagem e reutilização; Assegurar controle adequado no transporte e transbordo de resíduos e materiais perigosos; Implantar sistema funcional de fiscalização e controle ambiental aplicando sanções à disposição inadequada de resíduos e reconhecer e disciplinar a catação ambulante de materiais recicláveis. Na Tabela 3 são apresentadas as metas de curto prazo propostas no PMGIRS do Município de Cotiporã, o que já foi realizado até agora através do diagnóstico e propostas de melhorias nas ações para que o Plano seja bem executado ou para uma possível revisão. 
Quadro 3 - Apresentação de Metas de Curto Prazo presentes no PMGIRS em relação ao diagnóstico realizado e propostas de ações ao Município de Cotiporã

\begin{tabular}{|c|c|c|}
\hline Metas de Curto Prazo & Diagnóstico & Propostas \\
\hline $\begin{array}{c}\text { Elaboração de } \\
\text { Inventário Diagnóstico } \\
\text { detalhado referente aos } \\
\text { Resíduos Sólidos Urbanos }\end{array}$ & $\begin{array}{l}\text { O município está realizando um } \\
\text { inventário de dados referentes à } \\
\text { geração dos resíduos sólidos onde é } \\
\text { feita, trimestralmente, a pesagem } \\
\text { de resíduos gerados. }\end{array}$ & $\begin{array}{l}\quad \text { Realização de análise } \\
\text { gravimétrica, pesagem e } \\
\text { controle dos resíduos } \\
\text { mensalmente a fim de garantir } \\
\text { um melhor gerenciamento dos } \\
\text { resíduos. }\end{array}$ \\
\hline $\begin{array}{c}\text { Implementação de } \\
\text { Legislação Específica para } \\
\text { Gestão de Resíduos }\end{array}$ & $\begin{array}{l}\text { Lei } n^{\circ} 2.285 \text { de } 30 \text { de dezembro } \\
\text { de } 2013 \text { que o Plano Municipal de } \\
\text { Saneamento Básico. } \\
\text { O Município pretende criar uma } \\
\text { Lei para multar os cidadãos e } \\
\text { prestadores de serviços que não } \\
\text { praticarem o processo de coleta } \\
\text { seletiva. }\end{array}$ & $\begin{array}{l}\text { Legislações que } \\
\text { implementem a } \\
\text { responsabilidade individual dos } \\
\text { cidadãos, dos comerciantes e } \\
\text { indústrias do Município. }\end{array}$ \\
\hline $\begin{array}{c}\text { Implantação da Coleta } \\
\text { Seletiva, com abrangência } \\
\text { direta ou indireta em } 100 \% \\
\text { do Município }\end{array}$ & $\begin{array}{l}\text { A coleta seletiva foi } \\
\text { implementada em junho de 2013, } \\
\text { com abrangência total na área rural } \\
\text { e urbana do Município. }\end{array}$ & $\begin{array}{l}\text { Reorganização da coleta } \\
\text { seletiva a fim de seja realizada } \\
\text { por veículo adequado na região } \\
\text { rural e urbana, em dia semanal, } \\
\text { divulgado para os munícipes } \\
\text { para melhoria no processo de } \\
\text { reciclagem. }\end{array}$ \\
\hline $\begin{array}{l}\text { Campanha de Educação } \\
\text { Ambiental }\end{array}$ & $\begin{array}{l}\text { Foram realizadas diversas } \\
\text { campanhas de educação ambiental, } \\
\text { as mesmas vêm sendo realizadas } \\
\text { trimestralmente. } \\
\text { As campanhas educacionais são } \\
\text { realizadas via rádio, na igreja, } \\
\text { distribuição de folders, em escolas } \\
\text { com apresentações e trabalhos } \\
\text { educativos. } \\
\text { As campanhas que foram } \\
\text { realizadas instruíram os munícipes } \\
\text { a realizarem a coleta seletiva e } \\
\text { apresentou-se o Plano de } \\
\text { Saneamento Básico. }\end{array}$ & $\begin{array}{l}\text { Campanhas educativas a fim } \\
\text { de instruir os munícipes para a } \\
\text { realização de compostagem } \\
\text { doméstica, realizando uma } \\
\text { destinação correta dos resíduos } \\
\text { domésticos orgânicos, } \\
\text { diminuindo a quantidade de } \\
\text { resíduos dispostos em aterro e } \\
\text { campanhas educativas } \\
\text { reafirmando a importância da } \\
\text { coleta seletiva e campanhas de } \\
\text { recolhimento de resíduos } \\
\text { especiais. }\end{array}$ \\
\hline
\end{tabular}

A produção de resíduos é um fenômeno inevitável que ocorre diariamente em quantidades e composições que variam com seu nível de desenvolvimento econômico, com a sua população e seus diferentes estratos sociais. Os sistemas de limpeza urbana são de competência municipal e devem promover a coleta, o tratamento e a destinação ambiental e sanitária de forma correta e segura. No entanto esta tarefa não é fácil, devido à diversos fatores como: limitações de ordem financeira, deficiência na capacitação técnica e profissional, descontinuidade política e administrativa e ausência de controle ambiental (CEMPRE, 2000). 


\section{Conclusões}

De acordo com o PMGIRS de Cotiporã e com a realização dos estudos in loco foi possível constatar a necessidade de adequações no Plano, porém, é importante destacar eficiência na implantação e operação do mesmo, tendo em vista que houve um adiantamento no cumprimento da PNRS em comparação com grande parte dos municípios brasileiros, que realizam nesse último ano de prazo, o cumprimento da lei.

Em relação ao diagnóstico realizado para verificar a implantação e operação do PMGIRS no Município, deu-se visibilidade as etapas do gerenciamento destes resíduos e verificou-se os projetos e ações que vem sendo realizadas no cumprimento do Plano. A fim de tratar desses aspectos e de auxiliar na melhoria contínua da implantação e revisão do Plano, segue as seguintes recomendações, em especial, ações para minimização da geração de resíduos, para melhorias na segregação, acondicionamento, coleta, transporte e destino final adequado:

- Ao longo da implantação do Plano e suas revisões, seja ampliado o número de amostragens da caracterização quali-quantitativa de resíduos sólidos do Município, visando a obtenção de resultados mais seguros em relação ao diagnóstico e as características da composição gravimétrica dos resíduos sólidos do município.

- Coleta de dados de caracterização física dos resíduos gerados no município, através de caracterização gravimétrica e pesagem em intervalo determinado, assegurando a eficiência no gerenciamento dos resíduos sólidos e gerando um histórico de dados;

- Campanhas educativas visando à reeducação popular para redução da produção excessiva de embalagens;

- Adequações de coletores sob responsabilidade municipal, segundo a PNRS e a Resolução do CONAMA n 275 , proporcionando a adequada segregação, visando a excelência da coleta seletiva;

- Melhorias na coleta seletiva buscando um sistema eficaz e consciente, através de uma rota de coleta que atenda o Município na área rural e urbana, com o uso de veículos adequados, que comportem a quantidade de resíduos gerada, com o propósito de uma melhoria na gestão dos resíduos e melhor aproveitamento dos mesmos pela Associação de Catadores;

- Apoio técnico e financeiro à Associação de Catadores, proporcionando cursos capacitadores e disponibilizando conhecimento atualizado aos trabalhadores envolvidos no processo de triagem, para melhor aproveitamento dos materiais adquiridos junto à Coleta Seletiva;

- Elaborar campanhas educativas à fim de estimular a Compostagem Doméstica, principalmente no meio urbano;

- Implantar um processo de compostagem municipal, a fim de destinar adequadamente os resíduos orgânicos coletados e os resíduos de limpeza urbana e reciclá-los, proporcionando o beneficiando através do composto gerado (húmus), com aplicação do mesmo em canteiros municipais ou distribuição aos munícipes no cultivo de hortas e jardins;

- Estimular comerciantes e empresários no que diz respeito ao descarte correto de resíduos e logística reversa, através de campanhas educativas e reuniões onde incentivem a importância do processo de destinação adequada dos resíduos.

As atividades que estão sendo realizadas pela administração pública no cumprimento do plano são elogiáveis do ponto de vista organizacional e na condução das metas e ações, com a realização da coleta seletiva por parte da prefeitura, adequação das instalações da associação de catadores e o licenciamento da mesma, campanhas educacionais nas escolas e munícipes, utilização dos meios de comunicação no fornecimento de informações e campanhas educacionais aos cotiporanenses.

As recomendações propostas poderão ser utilizadas como ferramentas técnicas na revisão do PMGIRS, incorporadas às ações que já vem sendo realizadas e propiciando a atualização e adequação, rumo a um gerenciamento adequado dos resíduos sólidos, que vise a qualidade de vida e a sustentabilidade do ambiente. 


\section{Agradecimentos}

A Prefeitura Municipal de Cotiporã por ter fornecido os dados e a oportunidade de realizar o estudo do Plano Municipal de Gestão Integrada de Resíduos Sólidos.

\section{Referências}

ABRELPE. Panorama dos Resíduos Sólidos no Brasil. São Paulo, 2012. 116p. Disponível em: $<$ http://www.abrelpe.org.br/Panorama/panorama2012.pdf $>$. Acesso em: 26 de setembro de 2015.

ABRELPE. Panorama dos Resíduos Sólidos no Brasil. São Paulo, 2014. 120p. Disponível em: < http://www.abrelpe.org.br/Panorama/panorama2014.pdf >. Acesso em: 26 de setembro de 2015.

AQUINO, I. F. Proposição de uma rede de associações de catadores na região da grande Florianópolis: Alternativas de agregação de valor aos materiais recicláveis. Dissertação (Mestrado em Engenharia Ambiental) - Universidade Federal de Santa Catarina, Florianópolis, 2007.

BRASIL. Congresso. Senado. Decreto № 7.404, De 2010. Regulamenta a Lei N. 12.305, De 2010. Coleção de Leis Da República Federativa do Brasil. Brasília, DF, de 2 de Ago. 2010. Disponível em: $<$ http://www.planalto.gov.br/ccivil_03/_ato2007-2010/2010/decreto/d7404.htm>. Acesso em: 26 de setembro de 2015.

BRASIL. Coord. André Vilhena. Guia Da Coleta Seletiva De Lixo. Texto e Coordenação: André Vilhena; Ilustrações: Sandro Falsetti - São Paulo: Cempre - Compromisso Empresarial Para Reciclagem, 2013.

BRASIL. Plano Municipal de Gestão Integrada De Resíduos Sólidos. Cotiporã, 2012.

CEMPRE. Coord. André Vilhena. Lixo Municipal: Manual de Gerenciamento Integrado. Instituto de Pesquisas Tecnológicas (Ipt)/Cempre, São Paulo, 2000.

INSTITUTO BRASILEIRO DE GEOGRAFIA E ESTATÍSTICA - IBGE. Cidades@. Disponível Em: $<$ http://cidades.ibge.gov.br/painel/painel.php?lang=\&codmun=430595\&search=| cotipora $>$. Acesso em: 26 de setembro de 2015.

LOUREIRO, D. C.; AQUINO, A. M.; ZONTA, E.; LIMA, E. Compostagem e Vermicompostagem De Resíduos Domiciliar E Com Esterco Bovino Para A Produção De Insumo Orgânico. Pesquisa Agropecuária Brasileira, Brasília, Vol. 42, №.7, P.1043-1048, Jul. 2007.

MANO, E. B.; PACHECO, É. B. A. V.; BONELLI, C. M. C. Meio Ambiente, Poluição E Reciclagem. Engenharia Sanitária Ambiental, Vol.15, N.4, 2010.

MONTEIRO, J. H. P.; ZVEIBIL, V. Z.. Manual De Gerenciamento Integrado De Resíduos Sólidos. Rio De Janeiro: Ibam, 2001.

PESSIN, N.; CONTO, S. M.; TELH, M.; CADORE, J.; ROVATTI, D.; BOFF, R. E. Composição Gravimétrica De Resíduos Sólidos Urbanos: Estudo De Caso - Município De Canela - Rs. Congreso Interamericano De Ingeniería Sanitaria Y Ambiental, 30. Anais... Punta Del Este, 26-30 Nov. 2006. Disponível em: $<$ http://www.bvsde.paho.org/bvsaidis/uruguay30/BR05416 Pessin.pdf $>$. Acesso em: 26 de setembro de 2015.

RIBEIRO, Túlio F.; LIMA, Samuel C.. Coleta Seletiva De Lixo Domiciliar - Estudos De Caso. Caminhos Da Geografia, Vol.1dez/2000. 